\title{
Inflammation and fibrosis
}

\section{Rheumatoid arthritis - a virus disease?}

\author{
A. M. DENMAN \\ From the Division of Immunological Medicine, Clinical Research Centre, Harrow, Middlesex
}

We now understand many of the immunopathological processes that damage joints and other structures in rheumatoid arthritis and diffuse connective tissue diseases. Unfortunately, our progress in this direction is matched by an equal failure to identify the causes of all but a few of these disorders. Nevertheless, the stimuli which initiate these diseases are probably commonly encountered and tissue damage results when these immunopathological processes are abnormal in intensity and durationin other words, disease follows an unusual host reaction to a variety of environmental factors. This principle is well illustrated by the degenerative disease of the central nervous system, subacute sclerosing panencephalitis, which ensues in individuals who are unable to control the growth and dissemination of measles virus. An equivalent example in rheumatology is the onset of rheumatic fever and rheumatic carditis in susceptible individuals exposed to $\beta$-haemolytic streptococci. The central theme in the connective tissue diseases is the failure of patients with these disorders to limit the extent of their response to external insults. In nonsusceptible individuals these produce trivial injury and a short-lived reaction. Conversely, chronic disease ensues when these stimuli are not eliminated or the host reaction is uncontrolled.

Despite intensive efforts, there is no firm evidence that rheumatoid arthritis and other connective tissue diseases result from virus infections (Wilkes et al., 1973; Marmion and Mackay, 1977). The association between hepatitis B virus and polyarteritis nodosa in some patients with this disorder remains the only established instance. Moreover, in these attempts sophisticated techniques have been used for identifying latent or defective virus. Nevertheless, reluctance to abandon this theory is justifiable, mainly because it remains a plausible explanation of most of the clinical and laboratory findings. Firstly, the immunopathological features of experimental viral infections closely resemble those of spontaneous connective tissue diseases in man. These include circulating immune complexes and autoantibodies, arteritis with perivascular infiltrates of chronic inflammatory cells, and aberrant immune responses. Secondly, virus-infected cells initiate the whole spectrum of inflammatory and immune reactions which characterise the human disorders. These include complement activation by the classical and alternative pathways, which in turn initiate such processes as the immediate hypersensitivity reaction, platelet aggregation, and the chemotaxis of granulocytes and mononuclear phagocytes. Furthermore, virus-infected cells attract antibody either through virus-coded antigens on the cell membrane or because infected cells commonly carry receptors for the Fc portion of the immunoglobulin molecule. These cells also attract a cellular response in the form of both specifically sensitised $\mathrm{T}$ lymphocytes and non-sensitised $\mathrm{K}$ cells (Allison, 1974). Thirdly, there are various ways in which virus can evade elimination by the host despite initiating an immune response and thereby provoking immunopathological damage. There are several mechanisms by which virus infection could induce a persistent inflammatory response in the synovial membrane and these are considered in turn (see Figure). In each case rheumatoid arthritis would result from continued interaction between virus infection and the host response.

\section{Reaction to persistent viral antigen (Fig. a)}

Arthritis commonly accompanies acute virus infections. The simplest mechanism by which a transient infection might be followed by rheumatoid arthritis would be when arthrotropic virus persists in the joints of susceptible individuals and thereby provokes a continued immune response. Also virus might possibly reach the joint from the blood in the form of an immune complex formed between viral antigens and antibody. This process has been clearly demonstrated in arthritis after some bacterial infections. Chronic post-viral arthritis could result if the host response was unable to eliminate the original infection. This susceptibility might be 


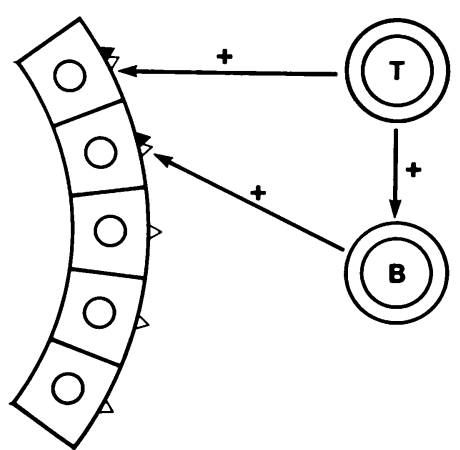

a

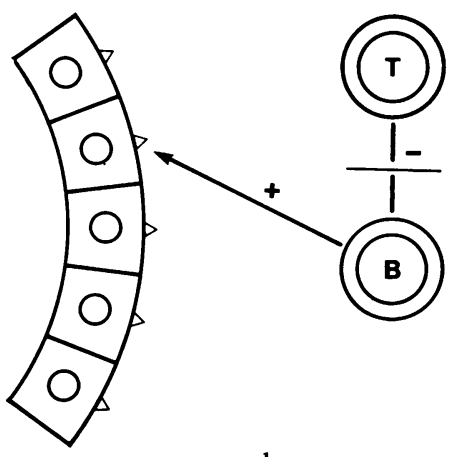

d

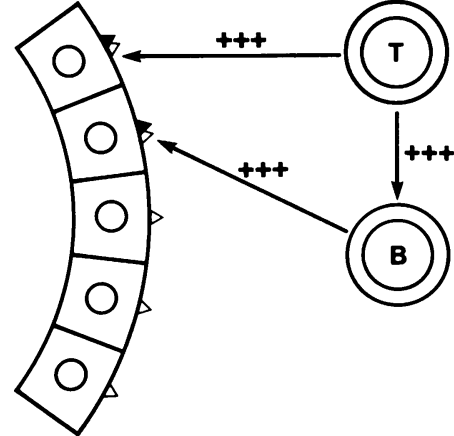

b

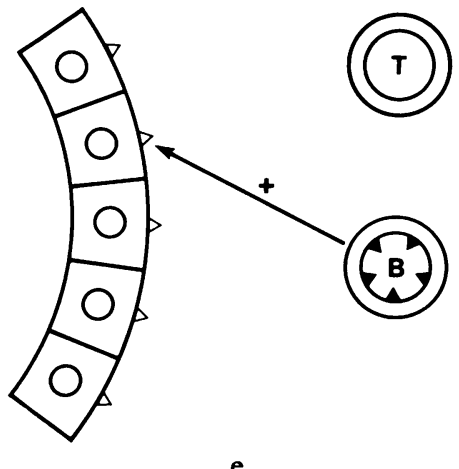

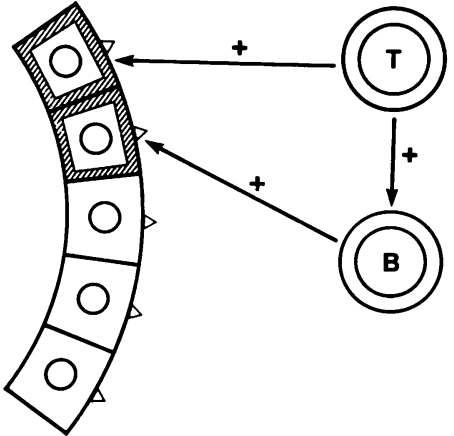

c

Fig. Putative mechanisms for the viral pathogenesis of rheumatoid arthritis. (a) Reaction to viral antigen. (b) Allergic reaction to altered antigen. (c) Reaction to altered membrane. (d) Defective suppressor mechanism. (e) Infected B-lymphocytes. $\triangle=$ Synovial cell antigen. $\Delta=$ Viral antigen. $T=T$-lymphocyte. $B=B$-lymphocyte. $+=$ Immune reaction, $T-B$ co-operation. $+++=$ Allergic response. $-=$ Suppressor $T$-cell action. (See text for detailed explanation.) determined by the titre to which virus grew initially in the infected joint thereby determining the number of cells carrying viral antigens.

Genetic factors undoubtedly determine the immunopathological consequences of virus infection in a number of species by regulating the extent and distribution of virus replication. This point is well illustrated by cytomegalovirus infection in different inbred mouse strains (Olding et al., 1976). In many strains this results in an acute infection with widespread tissue injury and death within four weeks of exposure. Other strains survive the initial infection but remain chronically infected and continue to shed readily detectable virus. The most interesting strains are those that remain latently infected with circulating immune complexes, causing immune complex glomerulonephritis, and, occasionally, autoantibodies to DNA. In these strains virus can be detected only with difficulty by cocultivating spleen cells with allogeneic feeder cells.

In some instances the extent to which virus grows in different hosts is governed by histocompatibility genes. Thus the pancreatic islet cells of mouse strains that are genetically susceptible to the diabetogenic effect of encephalo-myocarditis virus support the growth of this virus to far greater titres than similar cells from resistant mouse strains (Yoon et al., 1976). In man ethnic variation in resistance to rubella virus is correlated with HLA haplotypes (Honeyman and Mensor, 1974). Similarly there is an association between certain HLA antigens of the B series and the risk of developing hepatitis B antigenaemia after exposure to this virus (Hillis et al., 1977). Moreover, cellular resistance to infection with influenza A virus is influenced by HLA type (Spencer et al., 1978).

The distribution of infected cells as well as the extent of virus growth also influences the outcome of the infection. Thus B lymphocytes have usually been considered to be the principal if not the exclusive site of Epstein-Barr (EB) virus persistence. However, this virus also grows in epithelial cells in tissue culture, suggesting that an unusual distribution of it in some individuals could predispose to the later development of nasopharyngeal carcinoma (Leman et al., 1977). In addition to the well-known associations between some forms of postinfective arthritis and HLA B27 antigens of the D series have been linked with susceptibility to both rheumatoid arthritis (Stastny, 1976) and Sjögren's syndrome (Chused et al., 1977). Thus it is tempting to speculate that connective tissue diseases may be related to 
unusual patterns of viral persistence determined by histocompatibility antigens. However, this is unlikely to be the full explanation. For example, although antibody titres after rubella immunisation are in part related to HLA antigens, a similar association is not found with joint symptoms in subjects immunised with this virus (Griffiths, et al., 1977; Spencer et al., 1977).

The character of the immune response also determines the outcome of viral infections. The rheumatoid synovial membrane is densely infiltrated with chronic inflammatory cells, mostly $\mathrm{T}$ lymphocytes (Van Boxel and Paget, 1975). An important function of at least a subpopulation of $\mathrm{T}$ lymphocytes is to recognise cell membrane antigens, and particularly histocompatibility antigens, that have been altered by virus infection (Doherty and Zinkernagel, 1975). This recognition in turn generates a cytotoxic reaction which, in several animal models, is extremely efficient in limiting virus growth and dissemination although often at the expense of initiating an allergic reaction that damages the infected cells. Such responses in man may also be under genetic control since the cell-mediated immune response to vaccinia virus is related to HLA-Cw3 (de Vries et al., 1977).

It is pertinent to ask why, if the cellular response in rheumatoid arthritis is indeed directed at cells bearing viral antigens at their surface, this response should fail to eradicate or control the infectious process. Furthermore, other forms of immune response potentially directed against virus-infected cells are also operating in the affected tissue(Marmion and Mackay, 1977). A variety of factors are known to perpetuate viral infections. Some of these are purely anatomical in that the affected cells are totally inaccessible to host responses. This situation clearly obtains in the pathogenesis of virus infections of the central nervous system. Even when the responsible agents are able to elicit an immune response there may be no local response to the infected cells (Oldstone et al., 1977). Other factors are immunological in nature. Severe immunodeficiency dramatically predisposes to persistent virus infections and patients with agammaglobulinaemia are prone to develop ECHO virus infections of the central nervous system often accompanied by an inflammatory condition resembling dermatomyositis (Wilfert et al., 1977). Although it has been suggested that patients with connective tissue diseases have defective cellmediated immune responses to viruses (Wolf and Ziff, 1976), defects of comparable severity to those seen in patients with unequivocal primary immunodeficiency have not been detected. However, this possibility has not been extensively analysed. Moreover, even when virus infection provokes an apparently normal response the infection may persist because the immune response may be subverted (Mims, 1974).

Thus certain viruses spread from cell to cell despite the presence of antiviral antibody. The infected cells are not lysed by antiviral antibody and complement and these same viruses induce interferon poorly and are resistant to the antiviral action of interferon (Hook et al., 1976). The antibody response may itself be rendered ineffective. For example, the interaction of antibody to measles virus with viral antigens expressed on the surface of measlesinfected cells may lead to these antigens being deleted. As a result the infected cells are no longer lysed by antibody and complement acting in combination (Joseph and Oldstone, 1975). Furthermore, in prolonged virus infections antigenic drift can occur so that the initial antibody response against infected cells becomes progressively ineffective. This change in viral antigenicity has been observed in Iceland sheep infected with visna in which immunological responses were followed for a prolonged period (Petursson et al., 1976).

The antibody response may not invariably function to the advantage of the infected host. It has been suggested that by binding to viral antigens antibody prevents sensitised $\mathrm{T}$ lymphocytes from making contact with these antigens, thereby blocking their cytotoxic action. This possibility has been extensively discussed in relation to the survival of tumour cells. In addition, immunoglobulin has been shown to inhibit the growth of herpes simplex virus by binding to Fc receptors on the surface of cells infected with this virus (Costa et al., 1977). This kind of interaction may limit the expression of viral antigens on the surface of latently infected cells and thereby reduce the efficiency of a cell-mediated reaction. In addition, antibody may stimulate the growth of virus in lymphoreticular cells as in dengue virus infections (Halstead et al., 1976; Halstead and O'Rourke, 1977).

Other factors may operate to impair the efficiency of antiviral reactions mediated by $\mathrm{T}$ lymphocytes. It is firmly established that cytotoxic $\mathrm{T}$ lymphocytes generated during the course of viral diseases of mice kill only virus-infected target cells that bear H2 antigenic specificities common to both the cytotoxic cells and the infected cells (Doherty and Zinkernagel, 1975). There is still some debate about the reason for this restriction. It has been postulated that cytotoxic $T$ lymphocytes recognise not specific viral antigens but histo-compatibility antigens that have been modified by virus infection. Considerable evidence has accrued to support this view. Cells that express viral antigens but lack histocompatibility determinants are not attacked by cytotoxic $T$ lymphocytes even though such cells are still sus- 
ceptible to lysis by antibody and complement (Zinkernagel and Oldstone, 1976). Similarly only those cell lines infected with lymphocyticchoriomeningitis virus that express $\mathrm{H}-2$ genes are lysed by sensitised T lymphocytes (Doherty et al., 1977). The lysis of infected cells by specifically sensitised $T$ lymphocytes seems to be of critical importance during the early stages of at least some virus infections. $T$ lymphocytes sensitised against vaccinia virus appear only in the course of in-vivo infections by this virus and indeed seem to destroy infected target cells before infectious virus particles have been assembled (Zinkernagel and Althage, 1977).

The requirement for histocompatibility between target and effector cells has not been examined as systematically in man. However, similar restrictions have been shown with respect to the lysis of human cells infected with influenza virus (McMichael, et al., 1977) and, albeit less conclusively, by EB virus (Tursz et al., 1977). There is no detailed information about the pattern of histocompatibility and other antigens expressed on different cell types in the rheumatoid synovial membrane. Modulation of these antigens by virus or the immune response to virus could affect the sensitivity of infected cells to cytotoxic mechanisms.

Virus infections also interfere directly with immune responses and produce a variety of immunosuppressive effects. These are not accounted for by the obvious assumption that virus has a simple cytopathic effect on those lymphocytes whose function is impaired (Woodruff and Woodruff, 1975). Indeed, even under highly artefactual conditions in which lymphoreticular cells are exposed to high titres of virus in vitro only a small proportion of these cells become infected. Thus measles virus inhibits the reactivity of cultured human lymphocytes to several stimuli including plant mitogens, tuberculin purified protein derivate (PPD), and allogeneic lymphocytes. This inhibitory effect is exerted only in the early stages of culture and the immunosuppression clearly does not result from a cytopathic effect of the virus (Lucus et al., 1977). In-vivo experiments also show a discrepancy between the immunosuppressive effects of virus infection and obvious depletion of a functionally important lymphocyte population. Lactic dehydrogenase virus inhibits contact sensitivity to dinitrofluorobenzene in mice, an immune response mediated by circulating $T$ lymphocytes. Nevertheless, there is no obvious depletion of $T$ lymphocytes during acute infection with this virus (Michaelides and Simms, 1977).

The immuno-suppressive effects of acute virus $\mathrm{n}$ fection are obviously important if the ability of the host to mount an effective immune response against the invading virus is impaired. This principle is illustrated by the results of experiments with street rabies virus (Wiktor et al., 1977). Lethally infected mice fail to develop cytotoxic $T$ lymphocytes specific for target cells infected with rabies virus, whereas strong reactions of this nature are induced in mice surviving challenge with attenuated strains of rabies virus. The effects on the specific antiviral response may be long lasting. $T$ lymphocytes specifically cytotoxic for infected cells are not generated in mice infected with lymphocytic choriomeningitis virus when the potentially responding cells are exposed to a high level of syngeneic cells infected with this virus (Dunlop and Blanden, 1977).

A similarly specific suppression can be demonstrated by in-vitro experiments. These findings suggest that some viruses that grow in lymphoid tissues may delete all lymphocytes with the potential ability to generate a cytotoxic response against host cells infected by this virus, a state equivalent to 'clonal deletion' of the responding cells. Induced defects of this nature could perpetuate virus infections in man. In addition, such defects would make it difficult to interpret the results of clinical studies designed to incriminate certain viruses in the pathogenesis of chronic inflammatory diseases.

Such studies usually rely on evidence of increased rather than decreased immune responses to candidate viruses. Even relatively trivial virus infections produce disturbances in circulating lymphocyte populations. For example, in normal human subjects infected with wild-type influenza A virus or live, attenuated influenza vaccine the numbers of circulating $\mathrm{T}$ lymphocytes are greatly depressed (Scheinberg et al., 1976). The effects of persistent virus infection on functions mediated by $\mathrm{T}$ lymphocytes are not confined simply to those involving cytotoxic reactions against infected cells. Interferon is secreted by most populations of lymphoreticular cells, including $\mathrm{T}$ lymphocytes, and these populations interact synergistically to increase interferon production (Tsukui, 1977). The capacity of mice to produce interferon in response to interferon inducers becomes progressively impaired during the course of persistent infections with several viruses such as encephalomyocarditis virus and influenza A2 virus (Stringfellow, et al., 1977).

Thus there are numerous ways in which viruses evade elimination by the immune response of the host. This problem is compounded when one considers the potential survival of defective viruses that infect host cells without producing fully infectious progeny. Cells that are non-productively infected commonly fail to express surface antigens able to elicit an immune response. Defective particles may 
also produce atypical effects in infected cells, including the stimulation of host DNA synthesis, with resulting growth disorder (de Marchi and Kaplan, 1977). Mutant viruses with unusual growth characteristics often produce atypical immunopathological sequelae in infected hosts. Thus temperature-sensitive mutants of measles virus produce a pattern of central nervous system infection which is atypical in its distribution and longterm pathological consequences (Woyceichowska et al., 1977). Cyclical changes in rheumatoid arthritis could be accounted for by the irregular appearance of viral antigens on infected cells which only intermittently provoke an immune response.

Apparently therefore the host humoral and cellmediated immunity response to virus may fail to eliminate the infection. Moreover, an ineffective immune response may still be responsible for inflicting tissue damage. Nevertheless, it should not be assumed that the lymphocytes and monocytes that continue to infiltrate the sites of persistent infection are exclusively engaged in cytotoxic responses to infected cells. Various lymphocyte populations also mediate a direct antiviral effect in certain situations. This applies particularly to EB virus infections. $T$ lymphocytes from the blood of patients with infectious mononucleosis inhibit the transformation of susceptible cord blood lymphocytes by EB virus (Rickinson et al., 1977) while T lymphocytes from normal adults also inhibit the transformation of mature B lymphocytes by this same virus (ThorleyLawson et al., 1977). It has been suggested that T lymphocytes from individuals previously exposed to EB virus normally limit the growth of B lymphocytes in which the viral genome has been incorporated (Moss et al., 1977). Although the mechanism by which $T$ lymphocytes restrict the transforming activity of $E B$ virus is uncertain, interferon may be responsible: lymphocytes from subjects sensitised to the virus by natural infection release material with the characteristics of interferon which inhibits the ability of EB virus to transform cells (Lai et al., 1977).

Lymphocytes sensitised to other viruses such as cytomegalovirus in mice (Rytel and Hooks, 1977) and rubella in humans (Buimovici-Klein et al., 1977) also release interferon after in-vitro exposure to virus specific antigen. The amount of interferon released commonly indicates the degree of virusspecific immunity better than more traditional tests that measure lymphocyte proliferation in response to viral antigen. Probably, therefore, interferon secreted by $\mathrm{T}$ lymphocytes contributes to the antiviral activity mediated by this population.

Other mononuclear cell populations probably share this property since nude mice lacking $\mathrm{T}$ lym- phocytes still produce interferon when infected with lymphocytic choriomeningitis virus (Merigan et al., 1977). Furthermore, the in-vivo relevance of interferon to host resistance has been shown by experiments in which the virulence of encephalomyocarditis virus was greatly increased in mice treated with antiinterferon serum (Gresser et al., 1976). There are other antiviral mechanisms that do not necessarily involve T-lymphocyte cytotoxicity. Lymphoid cells from normal human donors lyse human fibroblasts infected with cytomegalovirus (Diamond et al., 1977). Again, blood lymphocytes from human volunteers inoculated with vaccinia virus specifically kill target cells infected with vaccinia virus. However, this cytotoxicity shows no restriction to genetically related target cells and is mediated by lymphocytes other than $\mathrm{T}$ cells. The reaction seems to be mediated by non-sensitised cytotoxic cells ( $\mathrm{K}$ cells) acting in combination with specific antibody (Perrin et al., 1977).

There are also 'natural killer' cells in mice which inactivate cells transformed by retroviruses that also do not require to be histocompatible with the target cells (Becker et al., 1976). In addition, some lymphocyte populations limit the growth of some viruses such as myxoviruses by allowing virus to enter the cell but not to complete a full growth cycle: infectious progeny are not released (Zisman and Denman, 1973).

Little attention has been paid to the possibility that the lymphocyte populations that infiltrate the rheumatoid synovial membrane form part of the elaborate host response to continued infection and that these cells are not exclusively committed to cytotoxic reactions. Attempts at demonstrating that the infiltrating cells are cytotoxic in vitro for fibroblasts derived from the rheumatoid synovial membrane of the same or other patients have been inconclusive (Griffiths et al., 1976). Defects in this range of antiviral effects could contribute to viral persistence.

\section{Allergic responses to viral antigens (Fig. b)}

Arthritis often complicates virus infections (Smith and Sanford, 1967; Rahai et al., 1976). Rubella is a notable example. What is usually an ephemeral joint infection could become a persistent arthritis if the infected individual mounted an allergic response to viral antigen (Fig. b). An allergic response would be analagous to allergic reactions in the respiratory tract and need not necessarily be marked by any increase in reaginic (IgE) antibody. There are indications that reaginic responses are enhanced in patients with rheumatic disorders (Goldman et al., 1976) but this needs further syste- 
matic investigation. At present there is little direct evidence bearing on this point but hypersensitivity reactions such as transient urticaria are noted not infrequently in virus infections in which acute self-limited polyarthitis is also a clinical feature.

\section{Persistent abnormalties in cells transiently infected by virus (Fig. c)}

It has been assumed that if rheumatoid arthritis has a viral aetiology the agent must persist in the synovial membrane in order to provoke a continuous immune response. However, it is possible to postulate forms of viral pathogenesis where this need not be the case. One mechanism would be the 'hit-and-run' effect of an agent (Fig. c). Viruses commonly alter the membranes of infected cells (Stohlman et al., 1975). It is quite plausible that these changes would persist not only in cells that no longer produced infective particles but also in the progeny of the cells that were originally infected. In these circumstances the association between rheumatoid arthritis and infection by a particular virus could not be made directly but might be inferred from epidemiological or immunological evidence.

There are interesting examples of persistent alterations in the biological behaviour of infected cells in which it may be difficult or impossible to detect other features of continued infection. Thus murine neuroblastoma cells infected with lymphocytic choriomeningitis virus contain reduced concentrations of the enzymes that make or degrade acetylcholine (Oldstone et al., 1977). These abnormalities persist even in cells that are no longer producing infectious virus. Related abnormalities are noted in mice inoculated with the same virus at birth. Conceivably, multiplying virus can alter the functions of host cells and thereby produce membrane changes which would attract an immune response. Such infections would not produce cell death and for prolonged periods might not release infectious particles. Also pertinent is the observation that the membranes of virus-infected cells injected into mice can provoke inflammatory disorders resembling autoimmune disease (Eaton and Almquist, 1977).

\section{Defective regulation of immune response to viral infections (Fig. d)}

The hypotheses so far considered postulate that virus alters the host cells in a manner that attracts a continued immune response. Equally possibly the response is triggered initially by a transient virus infection in the joints but perpetuated by defective regulation of the immune response (Fig. d). There has been much speculation about the mechanisms which suppress immune responses and the diseases that a defect in these mechanisms might provoke (Waksman, 1977). Although an elaborate series of feed-back mechanisms operates at all stages in the immune response suppressor $\mathrm{T}$ lymphocytes have received particular attention in the rheumatic diseases. There are claims that these cells are defective in patients with systemic lupus erythematosus (Bresnihan and Jasin, 1977), but the techniques for assaying 'suppressor' functions in man are still unsatisfactory and need critical evaluation (De la Concha et al., 1977).

Two principal kinds of defect can be proposed in relation to rheumatoid arthritis. The first postulates that the antibody response is appropriate in its initial specificity but the failure of normal suppressor mechanisms allows its prolongation long after the initial infection has subsided. Similar considerations apply to the regulation of cell-mediated immunity. The second kind of defect is an inappropriate stimulation of an immune response to tissue antigens or residual viral antigens in the affected joints which might involve either humoral or cell-mediated immune responses. Target cells infected with type A influenza virus, for example, display a common protein antigen with which antisera to different type A strains will react (Biddison et al., 1977). Accordingly sequential infections with different influenza $A$ strains could reactivate a reaction to residual membrane antigens of any strain.

There are also several examples of cross-reactions mediated by $\mathrm{T}$ lymphocytes. Cytotoxic $\mathrm{T}$ lymphocytes that kill target cells infected with influenza virus also fail to distinguish between serologically distinct type A viruses (Zweerink et al., 1977; Effros et al., 1977). Moreover, T lymphocytes display a wider range of cross-reactivity. Mouse $T$ lymphocytes sensitised to allogeneic stimulator cells are cytotoxic for trinitrophenyl-coupled target cells of the same strain as the cytotoxic lymphocytes (Lemonnier et al., 1977). These results indicate that $T$ lymphocytes sensitised to exogenous antigens could cross-react with modified histocompatibility antigens. It is noteworthy that cytotoxic cells with a wide range of specificity are generated in mice during the early stages of acute lymphocytic choriomeningitis virus infection (Welsh and Zinkernagel, 1977).

These examples illustrate the general principle that a wide range of transient viral infections could initiate immune reactions that might interact with structural components of host cells such as histocompatibility antigens or viral proteins incorporated in cell membranes. Moreover, $T$ lymphocyte reactions against histocompatibility antigens altered 
by virus infection could lead to true autoimmune reactions (Gleichmann and Gleichmann, 1976).

\section{Viral persistence in lymphoreticular cells (Fig. e)}

Possibly virus grows in selected lymphoid cell populations as well as in the affected joints. Inactivating these populations might both initiate and perpetuate the immune response and its immunopathological consequences. Replication in lymphoreticular cells is an obligatory stage in the pathogenesis of many virus infections. Measles virus, for example, grows readily in lymphocytes infected in vitro and cord blood mononuclear cells are particularly susceptible (Sullivan et al., 1975). In severe natural infections measles virus antigen may be detected in a high percentage of blood monuclear cells (Osunkoya et al., 1974). Moreover, lymphocytes seem to acquire viral antigens even in the course of banal infections by influenza virus (Wilson et al., 1976).

It is noteworthy that different viruses infect lymphocyte sub-populations in a selective manner. Thus EB virus absorbs preferentially to B lymphocytes with complement receptors (Yefenof et al., 1976) while in human cells the growth of herpes simplex type I virus is restricted to $T$ lymphocytes (Kirchner et al., 1977). Precise analysis allows the populations at risk to be defined more accurately. Thus by selectively infecting human tonsil cell cultures engaged in specific antibody synthesis it can be shown that helper $\mathrm{T}$ lymphocytes are particularly susceptible to infection by herpes simplex virus (Pelton et al., 1977).

It is well known that certain viruses persist in lymphoreticular cells indefinitely. Adenovirus can be cultured from tonsil cells long after the primary infection and the genome of EB virus is carried permanently in B lymphocytes. Indeed, the most striking examples of viral persistence in many species concern the DNA herpes viruses. A lymphotropic herpes virus related to EB virus has been identified in baboons, while in squirrel monkeys herpes virus saimiri is carried persistently in $T$ lymphocytes (Wright et al., 1976).

Additional manoeuvres may be needed to demonstrate virus. Thus cytomegalovirus in B lymphocytes is recoverable only after the infected cells have been cultured together with allogeneic cells (Olding et al., 1975). It is also noteworthy that cytomegalovirus infection of human lymphocytes leads to a more persistent infection than is observed with permissive fibroblasts (St Jeor and Weisser, 1977).

Should lymphoreticular cells prove to be the site of virus persistence in the connective tissue diseases how would this explain the characteristic immuno- pathological features of these disorders? The simplest view would be that these cells constitute a reservoir for the continued release of virus or virus products. Persistent infection of lymphocyte, however, could have more profound effects on the immune response itself. Virus infections can increase the antibody response to exogenous antigens, as is illustrated by experiments involving acute lactate dehydrogenase elevating virus in mice (Riley et al., 1976). But the more important issue concerns the possibility that viruses can infect potentially autoreactive lymphocytes of the $T$ or $B$ series and that the resulting uncontrolled proliferation of these cells would lead to autoimmune disease. This might follow the derepression of $\mathrm{V}$ genes coding for antibody synthesis or, alternatively, virus might alter the receptor for self-recognition on lymphocyte surfaces (Doherty et al., 1976).

There is already experimental evidence to suggest that the foregoing is not entirely speculative. Thymocytes from preleukaemic mice persistently infected with Moloney murine leukaemia virus are cytotoxic for syngeneic target cells but not for xenogeneic cells or virus-infected syngeneic cells (Proffitt et al,, 1976). These observations indicate that it is the subversion of lymphocyte recognition that initiates the autoaggressive behaviour. However, the most telling observations concern the interactions of EB virus with different lymphocyte populations. EB virus infects a minority of B lymphocytes in the blood of patients with infectious mononucleosis (Klein et al., 1975; Rocchi et al., 1977). Furthermore, there is some evidence that only a small population of $\mathbf{B}$ lymphocytes which have already begun to synthesise Ig are vulnerable to viral transformation (Steel et al., 1977).

This process, as already discussed, may be abetted by the temporary depression of $\mathrm{T}$ lymphocyte immunity at the height of the disease (Mangi et al., 1974) and which, if extreme, may produce a galaxy of lymphoproliferative disorders in susceptible families (Purtilo et al., 1977). EB virus induces polyclonal Ig production by human B cells in vitro (Rosen et al., 1977) and also potentiates antibody production against other antigens (Luzzati et al., 1977). Thus it is logical to conclude that the wide spectrum of autoantibodies that accompany this disease are stimulated by the same mechanism. Indeed, self-reactive B lymphocytes are induced by other stimuli which induce polyclonal activation of this population such as pokeweed mitogen (Primi et al., 1977).

Such observations merely point to lymphoreticular cells as plausible sites of virus persistence in the connective tissue diseases. Unfortunately no positive isolations have yet been achieved. For 
example, efforts to isolate virus from the lymphocytes of patients with connective tissue diseases by cocultivating or fusing lymphocytes with indicator cells have failed. Nevertheless, there is indirect evidence that such cells could be persistently infected. Using herpes simplex virus type $I$ as an example of a virus that invariably grows in stimulated lymphocytes from normal human subjects, we have observed that this virus commonly fails to grow in lymphocytes from patients with a variety of connective tissue diseases (Table) (Denman et al., 1976). The blood lymphocytes from most patients with rheumatoid arthritis support the growth of herpes simplex virus in a normal manner, with the exception of patients with early, acute disease. In contrast, cultured monuclear cells isolated from rheumatoid synovial effusions also fail to support the growth of this virus (Appleford and Denman, 1978). Presumably the abnormal behaviour of circulating lymphocytes reflects systemic changes induced by disease whereas, in rheumatoid arthritis the abnormality is mostly localised in the affected tissue.

These findings are open to several interpretations. Firstly, the underlying disease could induce an abnormality in the $T$ lymphocyte population which normally supports the growth of herpes simplex virus and thereby render these cells refactory to this virus. Conventional assays for $T$ lymphocyte function in these patients do not reveal defects of sufficient severity to account for the non-permissiveness. Moreover, even when the proportions of $T$ lymphocytes in cultures of normal blood mononuclear cells are artificially reduced to those found spontaneously in disease such cultures still allow herpes simplex virus to grow. However, only a small percentage of the $T$ lymphocytes in normal blood or tonsils normally permit virus growth (Pelton et al., 1977), and it is uncertain that the immunological competence of this population would be measured by standard tests. Secondly, non-permissiveness in disease could be attributed to interferon production. However, we have not detected increased amounts of interferon in these cultures using standard assays. Nevertheless, populations of $T$ lymphocytes can often be isolated from the blood mononuclear cells of such patients on the basis of size or surface markers which allow herpes simplex virus to grow in a normal fashion. Viral growth is abolished when those populations which are permissive in isolation are re-exposed to the other lymphocyte populations and cultured together with them. No such effects are observed when lymphocytes from normal donors are similarly manipulated. From these and related experiments we conclude that viral growth in potentially permissive cells is blocked by exposure to other lymphocyte populations or their products. This could indicate that the blood mononuclear cells and the infiltrating lymphocytes in these disease are producing an antiviral substance which is not classical interferon. These cells could thereby be contributing to the host defence against persistent infection.

Table Fate of herpes simplex virus in blood lymphocyte cultures from patients with different diseases (principal categories)

\begin{tabular}{|c|c|}
\hline Permissive* & Non-permissive \\
\hline $\begin{array}{l}\text { Normal controls (all ages) } \\
\text { Degenerative disorder } \\
\text { Neoplasia } \\
\text { Acute infections (including } \\
\text { septicaemias) } \\
\text { Chronic infections (including } \\
\text { tuberculosis) } \\
\text { Sarcoidosis } \\
\text { Hypersensitivity diseases (eg } \\
\text { erythema multiforme) } \\
\text { Most drug reactions } \\
\text { Rheumatoid arthritis }\end{array}$ & $\begin{array}{l}\text { Severe herpes simplex lesions } \\
\text { Acute viral arthritis } \\
\text { Infectious mononucleosis } \\
\text { Behcet's disease } \\
\text { Polyarteritis nodosa } \\
\text { Systemic lupus erythematosus } \\
\text { Dermatomyositis } \\
\text { Crohn's }\end{array}$ \\
\hline
\end{tabular}

*At least 2.0 logs of infectious virus synthesised/0.25 $\times 10^{\circ}$ cultured lymphocytes in 3 days (see Denham et al. (1976) for details).

†Excluding lymphoproliferative disorders.

Finally, there is the possibility that true interference by defective viral particles prevents the growth of herpes simplex virus in these cells. This notion is strengthened by the observation that other viruses such as measles virus and vesicular stomatitis virus grow normally in cultures that do not permit the growth of herpes simplex virus. But the occurrence of non-permissiveness to the same virus in several unrelated diseases makes it unlikely that failure of herpes simplex virus to grow gives more than a general indication that viral interference may be operating (Denman et al., 1977).

\section{Conclusion}

Conventional methods have failed to elucidate the pathogenesis of rheumatoid and connective tissue disease. A viral aetiology is worth pursuing because there are no features of the disease which are incompatible with this hypothesis. No agents have been reproducibly isolated from patients with these disorders, but there are several ways in which virus infection could initiate or perpetuate a persistent immune reaction in the affected joints or other structures without the causative agent being amenable to isolation or detection by even the most sophisticated techniques currently available. Lymphoreticular cells are a logical site for virus persistence although there is the additional problem that lymphoproliferative diseases may activate passenger viruses as an entirely secondary phenomenon. Model 
systems enable one to predict which lymphocyte populations are most likely to harbour specific viruses and to characterise such cells with respect to their immunological and general properties. These cells can be isolated from clinical material and their properties compared with those of the experimentally infected cells.

Finally, there are a variety of ways in which the infected host limits the spread and persistence of viral infections. These forms of host defence need systematic analysis in patients with connective tissue diseases in a search for aberrations which would allow abnormal virus persistence.

\section{References}

Allison, A. C. (1974). Interactions of antibodies, complement components and various cell types in immunity against viruses and pyrogenic bacteria. Transplantation Review, 19, 3-55.

Appleford, D., and Denman, A. M. (1978). In preparation.

Becker, S., Fenyo, E. M., and Klein, E. (1976). The 'natural killer' cell in the mouse does not require $\mathrm{H}-2$ homology and is not directed against type or groupspecific antigens of murine $\mathrm{C}$ viral proteins. European Journal of Immunology, 6, 882-885.

Biddison, W. E., Doherty, P. C., and Webster, R. G. (1977). Antibody to influenza virus matrix protein detects a common antigen on the surface of cells infected with type A influenza viruses. Journal of Experimental Medicine, 146, 690-697.

Bresnihan, B., and Jasin, H. E. (1977). Suppressor function of peripheral blood mononuclear cells in normal individuals and in patients with systemic lupus erythematosus. Journal of Clinical Investigation, 59, 106-116.

Buimovici-Klein, E., Weiss, K. E., and Cooper, L. Z. (1977). Interferon production in lymphocyte cultures after rubella infection in humans. Journal of Infectious Diseases, 135, 380-385.

Chused, T. M., Kassan, S. S., Opelz, G., Moutsopoulos, H. M., and Terasaki, P. I. (1977). Sjögren's syndrome associated with HLA-Dw3. New England Journal of Medicine, 296, 895-897.

Costa, J., Rabson, A. S., Yee, C., and Tralka, T. S. (1977). Immunoglobulin binding to herpes virus-induced $\mathrm{Fc}$ receptors inhibits virus growth. Nature (London), 269, 251-252.

De la Concha, E. G., Oldham, G., Webster, A. D. B., Asherson, G. L., and Platts-Mills, T. A. E. (1977). Quantitative measurements of T- and B-cell function in 'variable' primary hypogammaglobulinaemia: evidence for a consistent B-cell defect. Clinical and Experimental Immunology, 27, 208-215.

Denman, A. M., Appleford, D. J., Imrie, R. C., Kinsley, M. J., Pelton, B. K., and Schnitzer, T. (1977). Lymphocytes and virus infections in the connective tissue diseases. In Rheumatoid Arthritis, edited by J. L. Gordon and B. L. Hazleman, p. 233. Elsevier/NorthHolland Biomedical Press, Amsterdam.

Denman, A. M., Pelton, B. K., Appleford, D., and
Kinsley, M. (1976). Virus infections of lymphoreticular cells and auto-immune diseases. Transplantation Review, 31, 79-115.

Diamond, R. D., Keller, R., Lee, G., and Finkel, D. (1977). Lysis of cytomegalovirus-infected human fibroblasts and transformed human cells by peripheral blood lymphoid cells from normal human donors. Proceedings of the Society for Experimental Biology and Medicine, 154, 259-263.

Doherty, P. C., Gotze, D., Trinchieri, G., and Zinkernagel, R. M. (1976). Models for recognition of virally modified cells by immune thymus-derived lymphocytes. Immunogenetics, 3, 517-524.

Doherty, P. C., Solter, D., and Knowles, B. B. (1977). H-2 gene expression is required for T-cell-mediated lysis of virus-infected target cells. Nature (London), 266, 361-362.

Doherty, P. C., and Zinkernagel, R. M. (1975). A biological role for the major histocompatibility antigens. Lancet, 1, 1406-1408.

Dunlop, M. B. C., and Blanden, R. V. (1977). Mechanisms of suppression of cytotoxic $\mathrm{T}$-cell responses in murine lymphocytic choriomeningitis virus infection. Journal of Experimental Medicine, 145, 1131-1143.

Eaton, M. D., and Almquist, S. J. P. (1977). Autoimmunity induced by injection of virus-modified cell membrane antigens in syngeneic mice. Infection and Immunity, 15, 322-328.

Effros, R. B., Doherty, P. C., Gerhard, W., and Bennink, J. (1977). Generation of both cross-reactive and virusspecific $T$-cell populations after immunisation with serologically distinct influenza A viruses. Journal of Experimental Medicine, 145, 557-568.

Gleichmann, E., and Gleichmann, H. (1976). Diseases caused by reactions of $\mathrm{T}$ lymphocytes to incompatible structures of the major histocompatibility complex. I. Autoimmune hemolytic anaemia. European Journal of Immunology, 6, 899-905.

Goldman, J. A., Klimek, G. A., and Ali, R. (1976). Allergy in systemic lupus erythematosus: IgE levels and reaginic phenomenon. Arthritis and Rheumatism, 19, 669-676.

Gresser, I., Tovey, M. G., Bandu, M. T., Maury, C., and Brouty-Boyce, D. (1976). Role of interferon in the pathogenesis of virus disease in mice as demonstrated by the use of anti-interferon serum. I. Rapid evolution of encephalomyocarditis virus infection. Journal of Experimental Medicine, 144, 1305-1323.

Griffiths, M. M., Smith, C. B., Ward, J. R., and Klauber, M. R. (1976). Cytotoxic activity of rheumatoid and normal lymphocytes against allogeneic and autologous sonovial cells in vitro. Journal of Clinical Investigation, 58, 613-622.

Griffiths, M. M., Spruance, S. L., Ogra, P. L., Thompson, G. R., and De Witt, C. W.(1977). HLA and recurrent episodic arthropathy associated with rubella vaccination. Arthritis and Rheumatism, 20, 1192-1197.

Halstead, S. B., Marchette, J. J., Chow, J. S., and Lolekha, S. (1976). Dengue virus replication enhancement in peripheral blood leukocytes from immune human beings. Proceedings of the Society for Experimental Biology and Medicine, 151, 136-139. 
Halstead, S. B., and O'Rourke, E. J. (1977). Antibody enhanced dengue virus infection in primate leukocytes. Nature (London), 265, 739-741.

Hillis, W. D., Hillis, A., Bias, W. B., and Walker, W. G. (1977). Associations of hepatitis B surface antigenemia with HLA locus B specificities. New England Journal of Medicine, 296, 1310-1314.

Honeyman, M. C., and Menser, M. A. (1974). Ethnicity is a significant factor in the epidemiology of rubella and Hodgkin's disease. Nature (London), 251, 441-442.

Hooks, J. J., Burns, W., Hayashi, K., Geis, S., and Notkins, A. L. (1976). Viral spread in the presence of neutralising antibody: mechanisms of persistence in foamy virus infection. Infection and Immunity, 14, 1172-1178.

Joseph, B. S., and Oldstone, M. B. A. (1975). Immunologic injury in measles virus infection II. Suppression of immune injury through antigenic modulation. Journal of Experimental Medicine, 142, 864-876.

Kirchner, H., Kleinicke, C., and Northoff, H. (1977). Replication of herpes simplex virus in human peripheral T lymphocytes. Journal of General Virology, 37, 647-649.

Klein, G., Svedmyr, E., Jondal, M., and Persson, P. O. (1975). EBV-determined nuclear antigen (EBNA) positive cells in the peripheral blood of infectious mononucleosis patients. International Journal of Cancer, 17, 21-26.

Lai, P. K., Alpers, M.P., and Mackay-Scollay, E. M.(1977). Epstein-Barr herpes virus infection: inhibition by immunologically induced mediators with interferonlike properties. International Journal of Cancer, 20, 21-29.

Lemon, S. M., Hutt, L. M., Shaw, J. E., Li, J-L. H., and Pagano, J. S. (1977). Replication of EBV in epithelial cells during infectious mononucleosis. Nature (London), 268, 268-270.

Lemonnier, F., Burakoff, S. J., Germain, R. N., and Benecerraf, B. (1977). Cytolytic thymus-derived lymphocytes specific for allogeneic stimulator cells crossreact with chemically modified syngeneic cells. Proceedings of the National Academy of Sciences of the United States of America, 74, 1229-1233.

Lucas, C. J., Galama, J. M. D., and Ubels-Postma, J. (1977). Measles virus-induced suppression of lymphocyte reactivity in vitro. Cellular Immunology, 32, 70-85.

Luzzati, A. L., Hengartner, H., and Schreier, M. H. (1977). Induction of plaque-forming cells in cultured human lymphocytes by combined action of antigen and EB virus. Nature (London), 269, 419-420.

McMichael, A. J., Ting, A., Zweerink, H. J., and Askonas, B. A. (1977). HLA restriction of cell-mediated lysis of influenza virus-infected human cells. Nature (London), 270, 524-526.

Mangi, R. J., Niederman, J. C., Kelleher, J. E., Jr.. Dwyers, J. M., Evans, A. S., and Kantor, F. S. (1974). Depression of cell-mediated immunity during acute infectious mononucleosis. New England Journal of Medicine, 291, 1149-1153.

De Marchi, J. M., and Kaplan, A. S. (1977). The role of defective cytomegalovirus particles in the induction of host cell DNA synthesis. Virology, 82, 93-99.

Marmion, B. P., and Mackay, J. M. K. (1977). Rheumatoid arthritis and the virus hypothesis. In Bayer Symposium VI: Experimental Models of Chronic Inflammatory Diseases, edited by L. E. Glynn and H. D. Schlumberger, Springer, Berlin, p. 188.

Merigan, T. C., Oldstone, M. B. A., and Welsh, R. M. (1977). Interferon production during lymphocytic choriomeningitis virus infection of nude and normal mice, Nature (London), 268, 67-68.

Michaelides, M. L., and Simms, E. S. (1977). Immune responses in mice infected with lactic dehydrogenase virus. II. Contact sensitization to DNFB and characterization of lymphoid cells during acute LDV infection. Cellular Immunology, 29, 285-294.

Mims, C. A. (1974). Factors in the mechanism of persistence of viral infections. Progress in Medical Virology, 18, 1-14.

Moss, D. J., Scott, W., and Pope, J. H. (1977). An immunological basis for inhibition of transformation of human lymphocytes by EB virus. Nature (London), 268, 735-736.

Olding, L. B., Jensen, F. C., and Oldstone, M. B. A. (1975). Pathogenesis of cytomegalovirus infection. I. Activation of virus from bone marrow-derived lymphocytes by in-vitro allogeneic reaction. Journal of Experimental Medicine, 141, 561-572.

Olding, L. B., Kingsbury, D. T., and Oldstone, M. B. A. (1976). Pathogenesis of cytomegalovirus infection. Distribution of viral products, immune complexes and autoimmunity during latent murine infection. Journal of General Virology, 33, 267-280.

Oldstone, M. B. A., Holmstoen, J., and Welsh, R. M., Jr., (1977). Alterations of acetylcholine enzymes in neuroblastoma cells persistently infected with lymphocytic choriomeningitis virus. Journal of Cellular Physiology, 91, 459-472.

Oldstone, M. B. A., Lampert, P. W., Lee, S., and Dixon, F. J. (1977). Pathogenesis of the slow disease of the central nervous system associated with WM 1504 E virus. American Journal of Pathology, 88, 193-206.

Osunkoya, B. O. Adeleye, G. I., Adejumo, T. A., and Salimonu, L. S. (1974). Studies on leucocyte cultures in measles. II. Detection of measles virus antigen in human leucocytes by immunofluorescence. Archiv für die gesample Virusforchung, 44, 323-329.

Pelton, B. K., Imrie, R. C., and Denman, A. M. (1977). Susceptibility of human lymphocyte populations to infection by herpes simplex virus. Immunology, 32, 803-810.

Perrin, L. H., Zinkernagel, R. M., and Oldstone, M. B. A. (1977). Immune response in humans after vaccination with vaccinia virus: generation of a virus-specific cytotoxic activity by human peripheral lymphocytes. Journal of Experimental Medicine, 146, 949-969.

Pétursson, G., Nathanson, N., Georgsson, G., Panitch, H., and Palsson, P. A. (1976). Pathogenesis of Visna. I. Sequential virologic, serologic and pathologic studies. Laboratory Investigation, 35, 402-412.

Primi, D., Hammarström, L., Smith, C. I. E., and Möller, G. (1977). Characterization of self-reactive B cells by polyclonal B-cell activators. Journal of 
Experimental Medicine, 145, 21-30.

Proffitt, M. R., Hirsch, M. S., Ellic, D. A., Gheridian, B., and Black, P. H. (1976). Immunologic mechanisms in the pathogenesis of virus-induced murine leukemia. III. Target cell specificity of autoreactive thymocytes. Journal of Immonology, 117, 11-15.

Purchase, H. G., Gilmour, D. G., Romero, C. H., and Okazaki, W. (1977). Post-infection genetic resistance to avian lymphoid leukosis resides in B target cell. Nature (London), 270, 61-62.

Purtilo, D. T., De Florio, D., Jr., Hutt, L. M., Bhawan, J., Yang, J. P. S., Otto, R., and Edwards, W. (1977). Variable phenotypic expression of an X-linked recessive lymphoproliferative syndrome. New England Journal of Medicine, 297, 1077-1081.

Rahal, J. J., Millian, S. J., and Noriega, E. R. (1976). Coxsackie virus and adenovirus infection: association with acute febrile and juvenile rheumatoid arthiritis. Journal of the American Medical Association, 235, 2496-2501.

Rickinson, A. B., Crawford, D., and Epstein, M. A. (1977). Inhibition of the in-vitro outgrowth of EpsteinBarr virus-transformed lymphocytes by thymusdependent lymphocytes. from infectious mononucleosis patients. Clinical and Experimental Immunology, 28, 72-79.

Riley, V., Braun, W., Ishizuka, M., and Spackman, D. (1976). Antibody-producing cells: virus-induced alteration of response to antigen. Proceedings of the National Academy of Sciences of the United States of America, 73, 1707-1711.

Rocchi, G., de Felici, A., Ragona, G., and Heinz, A. (1977). Quantitative evaluation of Epstein-Barr virusinfected mononuclear peripheral blood leukocytes in infectious mononucleosis. New England Journal of Medicine, 296, 132-134.

Rosén, A., Gergely, P., Jondal, M., Klein, G., and Britton, S. (1977). Polyclonal Ig production after Epstein-Barr virus infection of human lymphocytes in vitro. Nature (London), 267, 52-54.

Rytel, M. W., and Hooks, J. J. (1977). Induction of immune interferon by murine cytomegalovirus. Proceedings of the Society for Experimental Biology and Medicine, 155, 611-614.

Scheinberg, M. A., Blacklow, N. R., Goldstein, A. L., Parrino, T. A., Rose, F. B., and Cathcart, E. S. (1976). Influenza: response of $\mathrm{T}$ cell lymphopenia to thymosin. New England Journal of Medicine, 294, 1208.

Smith, J. W., and Sanford, J. P. (1967). Viral arthiritis. Annals of Int ernal Medicine, 67, 651-659.

Spencer, M. J., Cherry, J. D., Powell, K. R., Mickey, M. R., Terasaki, P. I., Marcy, S. M., and Sumaga, C. V. (1977). Antibody responses following rubella immunization analysed by HLA and ABO types. Immunogenetics, 4, 363-372.

Spencer, M. J., Cherry, J. D., and Terasaki, P. I. (1976). HL-A antigens and antibody response after influenza A vaccination. Decreased response associated with HL-A type W16. New England Journal of Medicine, 294, 13-16.

Stastny, P. (1976). Mixed lymphocyte cultures in rheumatoid arthritis. Journal of Clinical Investigation, 57,
1148-1157.

Steel, C. M., Philipson, J., Arthur, E., Gardiner, S. E., Newton, M. S., and McIntosh, R. V. (1977). Possibility of EB virus preferentially transforming a subpopulation of human B lymphocytes. Nature (London), 270, 729-731.

St. Jeor, S., and Weisser, A. (1977). Persistence of cytomegalovirus in human lymphoblasts and peripheral leukocyte cultures. Infection and Immunity, 15, 402-409.

Stohlman, S. A., Wisseman, C.L., Jr., Eylar, O. R., and Silverman, D. J. (1975). Dengue virus-induced modifications of host cell membranes. Journal of Virology, 16, 1017-1026.

Stringfellow, D. A., Kern, E. R., Kelsey, D. K., and Glasgow, L. A. (1977). Suppressed response to interferon induction in mice infected with encephalomyocarditis virus, Semliki Forest virus, influenza A2 virus, herpes virus hominis type 2 or murine cytomegalovirus. Journal of Infectious Diseases, 135, 540-551.

Sullivan, J. L., Barry, D. W., Lucas, S. J., and Albrecht, P. (1975). Measles infection of human mononuclear cells. I. Acute infection of peripheral blood lymphocytes and monocytes. Journal of Experimental Medicine, 142, 773-784.

Thorley-Lawson, D. A., Chess, L., and Strominger, J. L. (1977). Suppression of in-vitro Epstein-Barr virus infection. Journal of Experimental Medicine, 146, 495508.

Tsukui, K. (1977). Influenza virus-induced interferon production in mouse spleen cell culture: $\mathbf{T}$ cells as the main producer. Cellular Immunology, 32, 243-251.

Tursz, T., Fridman, W. H., Senik, A., Tsapis, A., and Fellous, M. (1977). Human virus-infected target cells lacking HLA antigens resist $\mathrm{T}$-lymphocyte specific cytolysis. Nature (London), 269, 806-808.

Van Boxel, J. A., and Paget, S. A. (1975). Predominantly T-cell infiltrate in rheumatoid synovial membranes. New England Journal of Medicine, 293, 517-520.

Vries, R. R. P. de, Kreeftenberg, H. G., Loggen, H. G., and Van Rood, J. J. (1977). In-vitro immune responsiveness to vaccinia virus and HLA. New England Journal of Medicine, 297, 692-695.

Waksman, B. H. (1977). Tolerance, the thymus and suppressor $\mathrm{T}$ cells. Clinical and Experimental Immunology, 28, 363-374.

Welsh, R. M., and Zinkernagel, R. M. (1977). Heterospecific cytotoxic cell activity induced during the first three days of acute lymphocytic choriomeningitis virus infection in mice. Nature (London), 268, 646-648.

Wiktor, T. J., Doherty, P. C., and Koprowski, H. (1977). Suppression of cell-mediated immunity by street rabies virus. Journal of Experimental Medicine, 145, 16171622.

Wilfert, C. M., Buckley, R. H., Mohanakumar, T., Griffith, J. F., Katz, S. L., Whisnant, J. K., Eggleston, P. A., Moore, M., Treadwell, E., Oxman, M. N., and Rosen, F. S. (1977). Persistent and fatal centralnervous system echovirus infections in patients with agammaglobulinaemia. New England Journal of Medicine, 296, 1485-1489.

Wilkes, R. M., Simsarian, J. P., Hopps, H. E., Roth, H., Decker, J. L., Aptekar, R. G., and Meyer, H. M. 
(1973). Virologic studies on rheumatoid arthritis. Arthritis and Rheumatism, 16, 446-454.

Wilson, A. B., Planterose, D. N., Nagington, J., Park, J. R., Barry R. D., and Coombs, R. R. A. (1976). Influenza $\mathrm{A}$ antigens on human lymphocytes in vitro and probably in vivo. Nature (London), 259, 582-584.

Wolf, R. E., and Ziff, M. (1976). Lymphocyte responses to virus antigens in systemic lupus erythematosus. Arthritis and Rheumatism, 19, 1271-1277.

Woodruff, J. F., and Woodruff, J. J. (1975). The effect of viral infections on the function of the immune system. In Viral Immunology and Immunopathology, edited by A. L. Notkins, p. 393. Academic Press, New York.

Woyciechowska, J., Breschkin, A. M., and Rapp, F. (1977). Measles virus meningoencephalitis; immunofluorescence study of brains infected with virus mutants. Laboratory Investigation, 36, 233-236.

Wright, J., Falk, L. A., Collins, D., and Deinhardt, F. (1976). Mononuclear cell fraction carrying herpes virus saimiri in persistently infected squirrel monkeys. Journal of the National Cancer Institute, 57, 959-962.

Yefenof, E., Klein, G., Jondal, M., and Oldstone, M. B. A. (1976). Surface markers on human B- and T-lymphocytes. IX. Two-colour immunofluorescent studies on the association between EBV receptors and complement receptors on the surface of lymphoid cell lines. International Journal of Cancer, 17, 693-700.

Yoon, J. W., Lesniak, M. A., Fussganger, R., and Notkins, A. L. (1976). Genetic differences in susceptibility of pancreatic $\beta$ cells to virus-induced diabetes mellitus. Nature (London), 264, 178-180.

Zinkernagel, R. M., and Althage, A. (1977). Antiviral protection by virus-immune cytotoxic $T$ cells: infected target cells are lysed before infectious virus progeny is assembled. Journal of Experimental Medicine, 145, 644-651.

Zinkernagel, R. M, and Oldstone, M. B. A. (1976). Cells that express viral antigens but lack $\mathbf{H}-2$ determinants are not lysed by immune thymus-derived lymphocytes but are lysed by other antiviral immune attack mechanisms. Proceedings of the National Academy of Sciences of the United States of America, 73, 3666-3670.

Zisman, B., and Denman, A. M. (1973). Inactivation of myxoviruses by lymphoid cells. Journal of General Virology, 20, 211-223.

Zweerink, H. J., Courtneidge, S. A., Skehel, J. J., Crumpton, M. J., and Askonas, B. A. (1977). Cytotoxic $\mathrm{T}$ cells kill influenza virus infected cells but do not distinguish between serologically distinct type A viruses. Nature (London), 267, 354-356. 